\title{
Effect of Breathing Exercises on Quality of Recovery Among Postoperative Patients
}

\author{
Eman Elsayed Hussein ${ }^{1} \&$ Nadia Mohamed Taha ${ }^{1}$ \\ ${ }^{1}$ Medical Surgical Nursing, Faculty of Nursing, Zagazig University, Egypt \\ Correspondence: Eman Elsayed Hussein, lecturer of Medical Surgical Nursing Department, Faculty of Nursing, \\ Zagazig University, Egypt.
}

Received: November 23, 2018

Accepted: December 15, 2018 Online Published: December 21, 2018

doi:10.20849/ijsn.v3i3.525

URL: https://doi.org/10.20849/ijsn.v3i3.525

\begin{abstract}
Postoperative breathing exercises are widely important for patient to prevent postoperative respiratory complications. Breathing exercises had a highly positive effect on improving quality of recovery among post-operative patients. This study aimed to assess the effect of breathing exercises on quality of recovery among post-operative patients. Setting at Zagazig University Hospitals. Material and Method: a quasi-experimental (pre and posttest design). A purposive sample of total 258 study participants, 129 in experimental and 129 in control group based on inclusion and exclusion criteria. Data collection questionnaire were prepared with extensive review of previous literatures. Data collection through three tools includes, interviewing questionnaire sheet, postoperative quality scale and visual analogue scale of patient postoperative quality assessment scale. Breathing exercise (BE) was taught and practiced by the patients in experimental group and in control group routine postoperative care was followed. Result: postoperative quality rate was significantly different in experimental group were higher than in control group. Conclusion: post-operative breathing exercises improve postoperative quality.
\end{abstract}

Keywords: breathing exercises, quality of recovery, post-operative patients

\section{Introduction}

The surgical procedures in the abdominal area promote changes in pulmonary function and respiratory mechanics, leading to post-operative pulmonary complications (PPCs). Every day, worldwide, high volumes of patients undergo surgical procedures of one type or another. Irrespective of the type of procedure, postoperative recovery is an essential part of the patient experience. As a nurse specialized in the care of patients with acute pain, my work to follow up postoperative pain management involves daily meetings with patients recovering from surgery (Shashi and Rakesh, 2017).

Clearly reveal that they have concerns about several issues associated with postoperative recovery, both during hospitalization and after discharge. The current trend of rapid transition through the healthcare system means that patients are discharged quickly, shifting much of the responsibility for postoperative recovery to patients and their families. My observations of patients' experiences during hospitalization give me reason to question their readiness to handle their post-discharge recovery. To appropriately treat and support patients, according to their personal experiences and needs, we must enhance our knowledge and understanding of postoperative recovery. Assessing the impact of interventions on outcomes of genuine interest to patients requires subjective evaluation of patients' experiences (Bianchi, et al., 2004, Patrick, 2003).

Breathing exercises aim to correct breathing errors, reestablish a proper breathing pattern, increase diaphragm activity, elevate the amount of alveolar ventilation, reduce energy consumption when breathing and relieve the shortness of breath experienced by postoperative patients (Milgrom, et al., 2004, Meyerson, 2001). In order to combat this shortness of breath, breathing exercises used as an alternative treatment to bolster post-operative pulmonary function by teaching patients to utilize more of their lungs (Shenkman, et al., 1997). In their simplest form, breathing exercises consist of elongating and slowing down the inhalation and exhalation, which allow lung cancer patients to take deeper breaths that increase their intake of oxygen, rather than taking shallow breaths that only make use of the top half of their lungs (Westerdahl, et al., 2003).

Pulmonary complications after surgery are a significant cause of postoperative morbidity (Rady., et al., 1997, 
Massard., et al., 1998). Patients develop restrictive respiratory abnormalities with reduced lung volumes and impaired gas exchange in the early postoperative period.3-5 Atelectasis, bronchospasm, dyspnea, cough, pneumonia, respiratory failure and exacerbation of lung disease have all been reported as complications (Schuller and Morrow., 2000, Rady., et al., 1997, Brooks., 1995).

Breathing exercises involve breathing patterns that can be combined with upper limb and trunk movements, as well as thoracic cage maneuvers. These exercises aim to improve the patient's breathing pattern and increase lung expansion, respiratory muscle strength, functional residual capacity, and inspiratory reserve volume. Understanding the effect of these exercises is of fundamental importance to physical therapists as this knowledge will help them to select the best interventions for patients, the effectiveness of breathing exercises is rarely investigated (Samantha, 2014, Pryor and Ammani, 2008). Breathing exercises are applied once per hour for the first two post-operative days, while repetitions at each training session varied between 4 and 30 breaths during the first post-operative days (Yanez-Brage, et al., 2009).

\subsection{Significance of the Study}

Postoperative patient usually have different manifestation that affect their postoperative recovery including physical, psychological, emotional and pain. Utilization of breathing exercises during postoperative period is mainly reduced the stated manifestation and improve postoperative outcomes, those findings were supported by different studies including (Shashi and Rakesh, 2017, E. WESTERDAHL, 2015, E. Westerdahl and M. Fagevik, 2014, Urell, et al., 2012). Therefore, the researchers of the present study evaluates the effect of breathing exercises on quality of recovery among post-operative patients.

\subsection{Aim of the Study}

Evaluate the effect of breathing exercises on quality of recovery among post-operative patients.

\subsection{Research Hypotheses}

Patients who practiced breathing exercises will have better quality of recovery than those who do not.

\section{Subjects and Methods}

\subsection{Research Design}

A quasi experimental design was utilized to achieve the aim of the current study.

\subsection{Setting}

The present study was conducted at the surgical department at Zagazig University Hospitals, Egypt.

\subsection{Sample}

A purposive sample size was calculated using a simplified formula: $n=N / 1+N\left(e^{2}\right)$ total sample $=N=(720)=n=$ $\mathrm{N} / 1+\mathrm{N}(\mathrm{e}) 2=258$ providing direct which provided by Yamane (1997) to be care to surgical patient at the above mentioned setting, it was equally divided into two groups each has (129) patients, inclusion criteria adult patients free from medical disorders as (diabetes, heart disease, hypertension, etc....), admitted for abdominal surgery (hernia).

Tools of Data Collection: three tools used to collect data in order to achieve the aim of the study. The researchers developed three tools after reviewing the related literature.

\section{Tool I- interviewing questionnaire sheet:}

It included patient's demographic data such as age, educational level, educational qualification, and gender etc....,

\section{Tool II-postoperative quality scale:}

A 40-item questionnaire intended to measure quality of recovery, with items on a five point Likert scale (for positive items, 1'none of the time' to 5'all of the time'; for negative items the scoring was reversed).The items were then grouped according to various aspects (dimensions) of recovery: emotional state ( $n 9)$, physical comfort $(n 12)$, psychological support $(n 7)$, physical independence $(n 5)$ and pain $(n 7)$.

\section{Tool validity and reliability}

Test-retest reliability was done for the QoR-40. Cronbach's alpha was 0.92 for total QoR scale. And Cronbach's alpha for each dimension were: emotional state (0.86), physical comfort (0.83), psychological support (0.80), physical independence (0.80) and pain (0.77).

\section{Scoring system}


Total score of QoR scale was (200) scores, the total quality of recovery score was calculated as the following:-

Low quality of recovery------------- $<60 \%$ of total quality of recovery scores ( $<120$ scores).

Moderate quality of recovery ------60-75\% of total quality of recovery scores ( $<120-150$ scores).

High quality of recovery ------->75\% of total quality of recovery scores (> 150- scores).

Tool III-visual analogue scale

A visual analogue scale was utilized by the researchers to evaluate postoperative pain. Patients were asked to rate their overall pain using a 10-mm visual analogue scale (VAS), marked from 'no pain' to 'sever pain'.

\section{Total pain score}

It was scored as the following:

No pain---------------- (0)
Mild pain -------------- (1-4)
Moderate pain --------- (5-7)
Sever pain ------------- (8-10)

Pilot study: A pilot study was carried out on $10 \%$ of the total study sample to test the clarity, feasibility and applicability of the tools of the study. Pilot subjects were later included in the study as there was no radical modifications in the study tools.

Administrative and ethical considerations: The researchers explained the purposed of the study and their rights as a study participant, including anonymity and confidentiality, their rights to withdraw from the study at any time. Informed consent was obtained from the patients participated in the current study.

\section{Field work}

The study was implemented during the period from the first September 2015 to the end of September 2016 .The study tools were adapted and designed by the researchers after reviewing the relevant recent literatures. The researchers visited the study setting three days per week, for both intervention and control groups post-operative vital signs $\mathrm{SPo}_{2}$ without mask and postoperative respiratory complications include (cough, dyspnea, lung sound not clear) were assessed each hour until four hours post-operative pain was assessed by the researchers using visual analog scale. In addition, post-operative quality of recovery was evaluated for each group after 24 hours of operation for the study and control groups. For the study group, the researchers educated the patient the technique of breathing exercises including instructing breathe in slowly and as deeply as possible through the nose or mouth to take as much air as possible into lungs, hold breath for a while, and then breathe the air out slowly through mouth/device until have some air left in lungs". Instructions for expiration may vary from "a normal relaxed expiration" to a "slightly activated expiration" if the pursed lip technique is used. Plenty of time should be allowed for the inspiration and expiration, and enough time should be allowed between each breath to prevent fatigue. It is important that clear instructions be given, including a practical demonstration. In clinical practice, patients often perform breathing exercises without supervision; however, supervised breathing exercises may be more effective than self-directed breathing exercises. It is worth noting the patient's impression of comfort and benefit of the breathing exercises. Willingness to perform the exercises may increase if the patient feels the breathing exercises are working well.

Statistical design: Statistical analysis was done using IBM SPSS 22 statistical software package. Cleaning of data was done to be sure that there is no missing or abnormal data by running frequencies and descriptive statistics. Data was presented using descriptive statistics in the form of frequencies and percentages for categorical variables, means and standard deviations for continuous variables paired test, and chi-square. Pearson correlation analysis was used for assessment of the inter-relationships among quantitative variables. The significant level of all statistical analysis was at $<0.001 \&<0.05$ (P value).

\section{Results}

Table 1 presents personnel characteristics' of the studied participant in both intervention and control group, it is seen that there was no statistical significant between intervention and control regarding their age, educational qualification, residence and occupational status.

Table 2 illustrates the mean score of anthropometrics measures among the studied patients at both study and control groups, it was indicated that there was no statistical significant difference regarding their weight, height and body mass index. 
Table 3 shows the mean scores of vital signs among the studied patients, it was indicated that there was no statistical significant difference regarding their pulse,teperature,systolic and diastoylic blood pressure ( $p>0.05)$.

Table 4 illustrates the statistical significance of the respiratory outcomes among the studied patients in both the study and control group.it was revealed that there was a higly statistical difference between studied regarding coughing and not clearity of lung sound. Moreover there was a statistical significant difference regarding dysnea.

Table 5 indicates the mean scores of postoperative quality among the studeid patients,it was revealed that there was a highly statistical significant difference between studied patients regarding different dimension of postoperative quality of recovery including emotional,physical comfort ,psychological support, and pain $\left(\mathrm{p}<0.001^{* *}\right)$.in addition it was indicated that there was a significant difference was indicated between physical indepenence.

Table 6 illustares that there was no statistcal significat difference between both intervention and control groups regarding the respiatory rate.on the other hand there was a highly significant diffeence between them regarding $\mathrm{SPO}_{2}$ without mask. $(\mathrm{p}<0.001 * *)$

Table 7 reaveals that there was a highly significant diffeence between both intervention and control groups regarding the length of hospital stay $(\mathrm{p}<0.001 * *)$.

Figure 1 illustrates postoperative quality of recovery score among the studied patient in both study and control group, it was revealed that $42.6 \%$ of study group had a moderate score of quality of postoperative recovery, as compared by $63.6 \%$ of control group had a low score of quality of postoperative recovery.

Table 1. Personnel characteristics of the studied participant N (129)

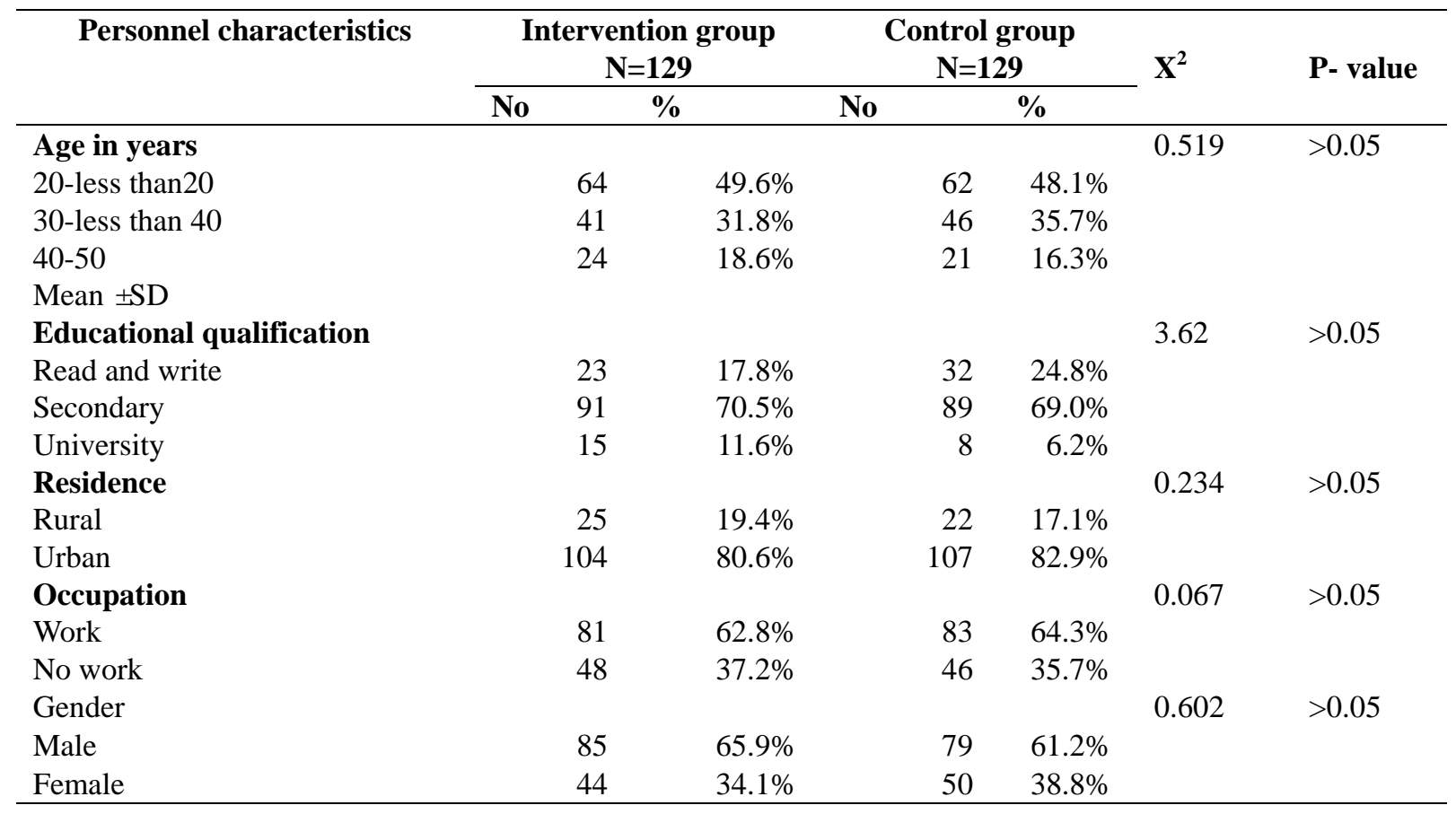

Table 2. Mean score of anthropometric measures of the studied sample

\begin{tabular}{|c|c|c|c|c|c|c|c|c|}
\hline \multirow{2}{*}{ Variable } & \multicolumn{3}{|c|}{$\begin{array}{c}\text { Intervention group } \\
\mathbf{N}=120\end{array}$} & \multicolumn{3}{|c|}{$\begin{array}{c}\text { Control group } \\
\mathrm{N}=120\end{array}$} & \multirow[t]{2}{*}{$\begin{array}{l}\text { Independent } \\
\text { T test }\end{array}$} & \multirow[t]{2}{*}{$P$ value } \\
\hline & Mean & \pm & SD & Mean & \pm & SD & & \\
\hline Weight & 1.6238 & \pm & .05240 & 1.6315 & \pm & .05818 & 1.11 & $>0.05$ \\
\hline Height & 72.0628 & \pm & 11.66128 & 72.2798 & \pm & 12.78992 & 0.142 & $>0.05$ \\
\hline Body mass index & 27.2839 & \pm & 3.82448 & 27.0471 & \pm & 3.82143 & 0.498 & $>0.05$ \\
\hline
\end{tabular}


Table 3. Distribution of vital signs mean score of the studied sample

\begin{tabular}{|c|c|c|c|c|c|}
\hline \multirow[t]{2}{*}{ Vital signs } & \multirow{2}{*}{$\begin{array}{l}\text { Times } \\
\text { assessment }\end{array}$} & \multirow{2}{*}{$\begin{array}{l}\text { Intervention group } \\
\text { Mean } \pm \text { SD }\end{array}$} & \multirow{2}{*}{$\begin{array}{l}\text { Control group } \\
\text { Mean } \pm \text { SD }\end{array}$} & \multirow{2}{*}{$\begin{array}{l}\text { Independent } \\
\text { T test }\end{array}$} & \multirow[t]{2}{*}{$P$ value } \\
\hline & & & & & \\
\hline \multicolumn{6}{|l|}{ Temperature } \\
\hline & $1^{\text {st }}$ hour & $37.1279 \pm .32039$ & $36.7087 \pm 3.01678$ & 0.696 & $>0.05$ \\
\hline & $2^{\text {nd }}$ hour & $37.1938 \pm .32662$ & $37.1260 \pm .33905$ & 0.793 & $>0.05$ \\
\hline & $3^{\text {rd }}$ hour & $37.1744 \pm .34602$ & $37.1811 \pm .29324$ & 0.227 & $>0.05$ \\
\hline & $4^{\text {th }}$ hour & $37.1938 \pm .32662$ & $37.1260 \pm .33905$ & 0.310 & $>0.05$ \\
\hline \multicolumn{6}{|l|}{ Pulse } \\
\hline & $1^{\text {st }}$ hour & $73.9070 \pm 6.72384$ & $74.4646 \pm 6.08119$ & 1.56 & $>0.05$ \\
\hline & $2^{\text {nd }}$ hour & $73.9070 \pm 6.72384$ & $74.5433 \pm 6.08766$ & 1.63 & $>0.05$ \\
\hline & $3^{\text {rd }}$ hour & $75.9457 \pm 5.62126$ & $75.7874 \pm 5.51999$ & 0.167 & $>0.05$ \\
\hline & $4^{\text {th }}$ hiur & $76.4729 \pm 5.59726$ & $76.6850 \pm 5.34627$ & 1.63 & $>0.05$ \\
\hline \multicolumn{6}{|c|}{ Systolic blood pressure } \\
\hline & $1^{\text {st }}$ hour & $113.8372 \pm 7.61658$ & $113.2946 \pm 7.19419$ & 0.588 & $>0.05$ \\
\hline & $2^{\text {nd }}$ hour & $115.5039 \pm 7.52197$ & $115.1163 \pm 7.69195$ & 0.409 & $>0.05$ \\
\hline & $3^{\text {rd }}$ hour & $118.0233 \pm 6.50777$ & $117.0930 \pm 6.14594$ & 1.18 & $>0.05$ \\
\hline & $4^{\text {th }}$ hiur & $117.2868 \pm 10.66184$ & $116.8605 \pm 5.55757$ & 0.403 & $>0.05$ \\
\hline \multicolumn{6}{|c|}{ Diastolic blood pressure } \\
\hline & $1^{\text {st }}$ hour & $73.3721 \pm 9.39421$ & $72.2558 \pm 15.74319$ & 0.692 & $>0.05$ \\
\hline & $2^{\text {nd }}$ hour & $75.6977 \pm 5.77928$ & $75.1628 \pm 5.80785$ & 0.741 & $>0.05$ \\
\hline & $3^{\text {rd }}$ hour & $74.6279 \pm 6.93504$ & $76.1783 \pm 6.0897$ & 1.90 & $>0.05$ \\
\hline & $4^{\text {th }}$ hiur & $76.1395 \pm 5.68131$ & $76.7054 \pm 5.43628$ & 0.817 & $>0.05$ \\
\hline
\end{tabular}

Table 4. Distribution of respiratory out comes

\begin{tabular}{|c|c|c|c|c|c|c|c|c|c|c|}
\hline & \multicolumn{4}{|c|}{ Intervention group $(\mathrm{n}=129)$. } & \multicolumn{4}{|c|}{ Control group (129). } & \multirow{3}{*}{$\mathbf{X}^{2}$} & \multirow{3}{*}{ P-value } \\
\hline & \multicolumn{2}{|c|}{ Yes } & \multicolumn{2}{|c|}{ No } & \multicolumn{2}{|c|}{ Yes } & \multicolumn{2}{|c|}{ No } & & \\
\hline & No & $\%$ & No & $\%$ & No & $\%$ & No & $\%$ & & \\
\hline Cough & 48 & $37.2 \%$ & 81 & $62.8 \%$ & 80 & $62.0 \%$ & 49 & $38.0 \%$ & 15.87 & $<0.001 * *$ \\
\hline Lung sound is not clear & 28 & $21.7 \%$ & 101 & $78.3 \%$ & 84 & $65.1 \%$ & 45 & $34.9 \%$ & 49.47 & $<0.001 * *$ \\
\hline Dyspnea & 33 & $25.6 \%$ & 96 & $74.4 \%$ & 52 & $40.3 \%$ & 77 & $59.7 \%$ & 6.33 & $<0.05^{*}$ \\
\hline
\end{tabular}

Table 5. Distribution of postoperative quality of recovery among studied patients

\begin{tabular}{|c|c|c|c|c|c|}
\hline \multirow[t]{2}{*}{ Variables } & \multirow[t]{2}{*}{ Score } & Intervention group & Control group & \multirow{2}{*}{$\begin{array}{l}\text { Independent t } \\
\text { test }\end{array}$} & \multirow[t]{2}{*}{$P$ value } \\
\hline & & Mean \pm SD & Mean \pm SD & & \\
\hline Emotional state (9 items) & 45 & $29.4729 \pm 4.61837$ & $17.5814 \pm 5.83724$ & 18.14 & $<0.001 * *$ \\
\hline Physical comfort ( 12 items) & 60 & $28.7519 \pm 6.10716$ & $23.4341 \pm 8.21093$ & 5.90 & $<0.001 * *$ \\
\hline Psychological support (7 items) & 35 & $20.2868 \pm 5.45463$ & $13.4961 \pm 4.84304$ & 10.57 & $<0.001 * *$ \\
\hline Physical independence (5 items) & 25 & $11.2403 \pm 4.89703$ & $9.7829 \pm 3.37954$ & 2.78 & $<0.05^{*}$ \\
\hline Pain & 35 & $19.7519 \pm 5.18265$ & $13.5891 \pm 4.53220$ & 10.16 & $<0.001 * *$ \\
\hline Global QoR-40 & 200 & $109.5039 \pm 18.49203$ & $77.8837 \pm 24.28079$ & 11.76 & $<0.001 * *$ \\
\hline
\end{tabular}

Table 6. Distribution of respiratory parameters among studied patients

\begin{tabular}{lllll}
\hline Variables & Intervention group & Control group & $\begin{array}{l}\text { Independent } \\
\text { test }\end{array}$ & P value \\
\cline { 2 - 5 } & Mean \pm SD & Mean \pm SD & 0.291 & $>0.05$ \\
\hline Respiration (breath /minute) & $23.4574 \pm 3.73959$ & $23.3256 \pm 3.52704$ & & $<0.001 * *$ \\
$\mathrm{SPO}_{2}$ without mask & $99.2868 \pm .83098$ & $98.5426 \pm 1.72304$ & 4.41 & $<$ \\
\hline
\end{tabular}


Table 7. Distribution of length of hospital stay among studied patients

\begin{tabular}{|c|c|c|c|c|c|c|}
\hline \multirow[t]{2}{*}{ Variable } & \multicolumn{2}{|c|}{ Intervention group } & \multicolumn{2}{|c|}{ Control group } & \multirow{2}{*}{$\mathrm{X}^{2}$} & \multirow{2}{*}{ P-value } \\
\hline & No & $\%$ & No & $\%$ & & \\
\hline length of hospital stay (in hours) & & & & & 32.88 & $<0.001 * *$ \\
\hline 24- $<48$ hours & 65 & $50.4 \%$ & 30 & $23.3 \%$ & & \\
\hline 48-72 hours & 64 & $49.6 \%$ & 81 & $62.8 \%$ & & \\
\hline$>72$ hours & 0 & $0.0 \%$ & 18 & $14.0 \%$ & & \\
\hline
\end{tabular}

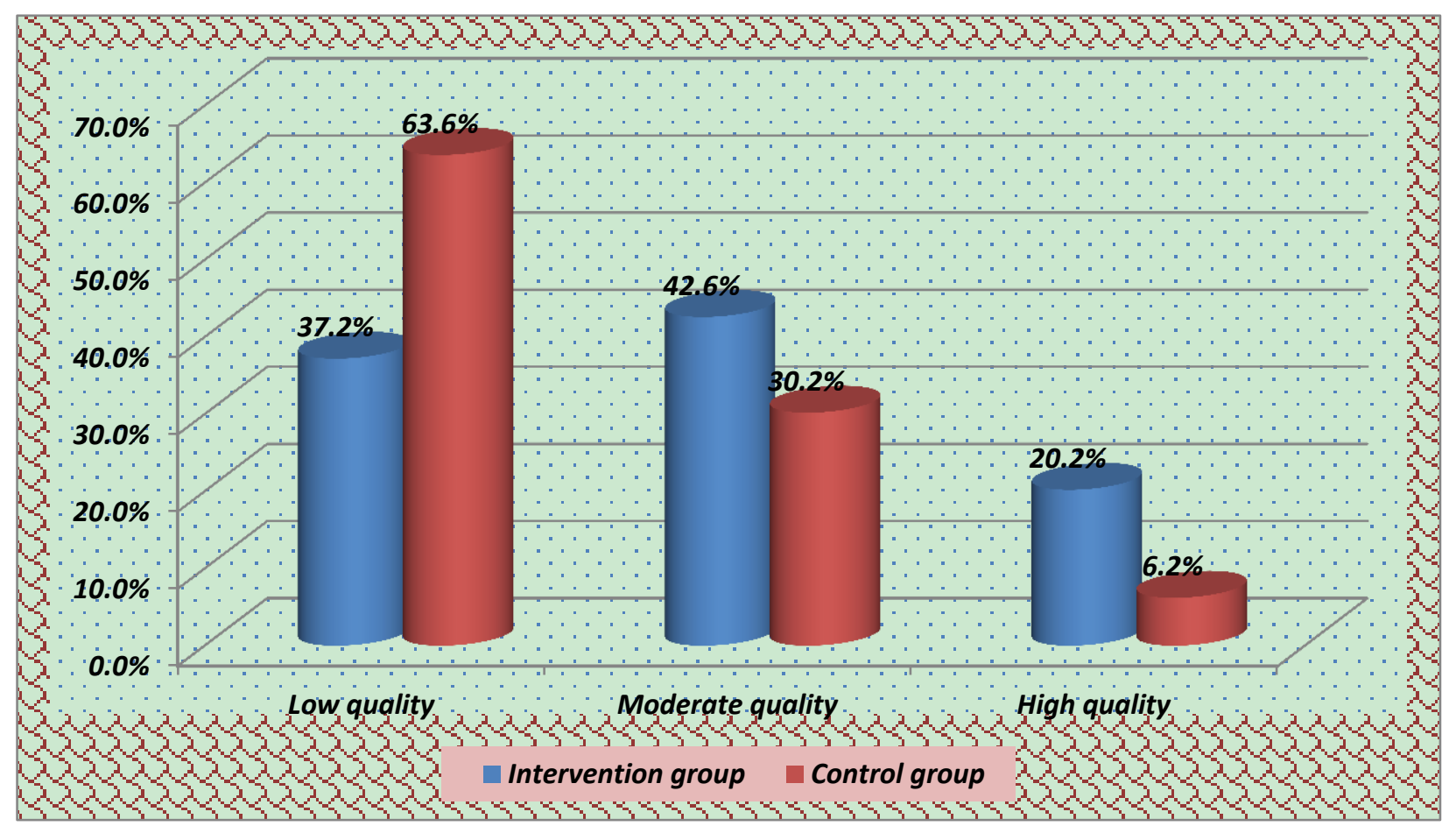

Figure 1. Percentage distribution of postoperative quality of recovery score among the studied patients

\section{Discussion}

The result of the current study supported the stated hypothesis that patient who practice-breathing exercises had a better quality of recovery than those who do not and the mean score of quality of recovery was higher among patient practice breathing exercises than among patient in control group.

As regarding personal characteristics of the studied patient at both intervention and control groups, the present study findings indicated that no statistical significant between intervention and control regarding their age, educational qualification, residence and occupational status. These finding supported by (Shashi and Rakesh, (2017), in the study to assess the effect of "deep breathing exercise and its outcome among patient with abdominal surgery." It was illustrated that there was no statistical significant between study and control regarding their age, educational qualification, residence (E. Westerdahl and M. Fagevik Olsén, 2014).

As regarding the mean score of anthropometrics measures among the studied patients at both study and control groups, it was indicated that there was no statistical significant difference regarding their weight, height and body mass index.

In relation to the mean scores of vital signs among the studied patients, it was indicated that there was no statistical significant difference regarding their pulse, teperature, systolic and diastoylic blood pressure. These finding are agreed with Shashi and Rakesh, (2017), who included that there was no statistical significant difference between both study and control group regarding their respiratory rate.

Moreover the present study findings indicated that SPO2 was high among experimental group than the patients without breathing exercises, in both the group had shown a significant difference from pre-operative to post-operative phase. These finding are agreed with Shashi and Rakesh, (2017), also reported of better lung capacity postoperatively in-patient with breathing exercises. 
At the present study, all the patients were assessed for post-operative complications specifically presence of cough, lung sound isn't clear, difficulty in breathing. It was revealed that there was a highly statistical difference between studied regarding coughing and not clearity of lung sound. Moreover there was a statistical significant difference regarding dysnea. Study by Wren and colleagues. These finding are agreed with (Wren, et al., 2010, Shi., 2006), in the study to "Postoperative pneumonia-prevention program for the inpatient surgical ward." experimented with a pulmonary care program to reduce the post-operative respiratory complications.

Breathing exercises are applied once per hour for the first two post-operative days, while repetitions at each training session varied between 4 and 30 breaths during the first post-operative days. There is no agreement on how often breathing exercises should be performed, but the physiotherapists' most commonly recommendation of hourly treatment in the present study, is consistent with the current literature on the suggested frequency (Yanez-Brage, et al., 2009, Muller, et al., 2006, Lumb, et al., 2005, Westerdahl, et al., 2005).

As regarding the effect of breathing exercises on postoperative quality of recovery, the present study indicated that the postoperative quality of recovery was higher among study group than compared with control group, these findings came in the same line with (Shashi and Rakesh., 2017), this may be due to improvement of emotional status .As the level of anxiety and distress was decreased. These findings are supported by (Bjo"rn., 2015), in the study " analyze prevalence and predictors of QOR after day surgery on the fourth postoperative day", who indicated that, anxiety is perhaps the best explored psychological determinant in predicting post operative pain. A highly anxious client may appear to be more distresses and affected by pain. Many patients do not make it important to complain pain and nurses do not observe or use pain scales to monitor, whereas the vital signs are assessed on regular basis. Also improvement of physical comforted, Psychological support, Physical independence were high among the intervention group that help them to feel more relax and comfort that subsequently improve their level of recovery quality.

More over the postoperative pain were reduced among the intervention group as compared with the study group that subsequently improve quality of recovery. These findings agreed with (Bozorg et al.,2018) in the study to assess" The Effect of Rhythmic Breathing on Pain of Dressing Change in Patients with Burns Referred to Ayatollah Mousavi Hospital "it was indicated that use of rhythmic breathing technique was effective as a non-pharmacological method to reduce pain of change dressing. According to gate control theory, it can be explained this way when the input from descending and inhibitory fibers of brain was more than stimulus input of small fibers, the gate is closed and the pain data cannot be Accordingly, relaxation can reduce or complete remove the pain through inhibitory impulses of the cerebral cortex and thalamus and thus closing the gate. In addition, based on gate control theory, feeling out of control conditions can cause opening the gate through the cerebral cortex and increase different aspects of pain. As a result, burns patients need to feel they have control over their position. For this purpose, learning relaxation methods can create increasing feeling of personal control on pain and hence patients can play active role in learning and implementing pain management skills instead of being passive receiver of medical interventions. Relaxation reduces pain and consequently anxiety by releasing endorphins.

\section{Conclusion}

Based on the result of the current study, the present study concluded that postoperative breathing exercises improve quality of recovery among postoperative patients.

\section{Recommendations}

Breathing exercises should be added postoperative to postoperative patients. The patients need to determine the role of postoperative breathing exercises in reducing such events.

\section{References}

Bianchi, R., Gigliotti, F., Romagnoli, I., Lanini, B., Castellani, C., Grazzini, M. et al. (2004). Chest wall kinematics and breathlessness during pursed-lip breathing in patients with COPD. Chest, 125, 459-465. https://doi.org/10.1378/chest.125.2.459

Bjo"rn Stessel, M.D., Audrey, A.F., Elbert, A.J., Daisy M.N. Hoofwijk, M.D., Hans-Fritz, G., \& Wolfgang F.F.A.B. (2015). Prevalence and Predictors of Quality of Recovery at Home After Day Surgery. US National Library of Medicine National Institutes of Health, 94(39).

Bozorg-Nejad, M., Azizkhani, H., Mohaddes Ardebili, F., Mousavi, S.K., Manafi, F., \& Hosseini, A.F. (2018, January). The Effect of Rhythmic Breathing on Pain of Dressing Change in Patients with Burns Referred to Ayatollah Mousavi Hospital. World J. Plast Surg., 7(1), 51-57.

Brooks-Brunn, J.A. (1995). Postoperative atelectasis and pneumonia. Heart Lung, 24, 94-115. https://doi.org/10.1016/S0147-9563(05)80004-4

Lumb, A.B., \& Nunn, J.F. (2005). Nunn's applied respiratory physiology (6th ed.). Oxford: Elsevier/ButterworthHeinemann. 
Massard, G., \& Wihlm, J.M. (1998). Postoperative atelectasis. Chest Surg. Clin. N. Am., 8, 503-528.

Meyerson, J., Thelin, S., Gordh, T., \& Karlsten, R. (2001). The incidence of chronic post-sternotomy pain after cardiac surgery-a prospective study. Acta Anaesthesiol Scand, 45, 940-944. https://doi.org/10.1034/j.1399-6576.2001.450804.x

Milgrom, L.B., Brooks, J.A., Qi, R., Bunnell, K., Wuestfeld, S., \& Beckman, D. (2004). Pain levels experienced with activities after cardiac surgery. Am. J. Crit. Care, 13, 116-125.

Muller, A.P., Olandoski, M., Macedo, R., Costantini, C., \& Guarita-Souza, L.C. (2006). Comparative study between intermittent (Muller Reanimator) and continuous positive airway pressure in the postoperative period of coronary artery bypass grafting. Arq Bras Cardiol, 86, 232-239.

Patrick, D.L. (2003). Patient-reported outcomes (PROs). An organizing tool for concepts, measures and applications. Qual Life Newsl, 31, 1-5.

Pryor, J.A., \& Ammani Prasad, S. (2008). Physiotherapy for respiratory and cardiac problems: adults and paediatrics (4th ed.). Edinburgh: Elsevier/Churchill Livingstone.

Rady, M.Y., Ryan, T., \& Starr, N.J. (1997). Early onset of acute pulmonary dysfunction after cardiovascular surgery: risk factors and clinical outcome. Crit. Care Med., 25, 1831-1839. https://doi.org/10.1097/00003246-199711000-00021

Samantha, T., Grams, L.M., Ono, M.A., Noronha, C.I.S., \& Schivinski, E.P. (2014, May). Breathing exercises in upper abdominal surgery: a systematic review and meta-analysis. Rev Bras Fisioter, São Carlos, 16(5), 345-353. Camila Isabel Santos Schivinski.

Schuller, D., \& Morrow, L.E. (2000). Pulmonary complications after coronary revascularization. Curr Opin Cardiol, 15, 309-315. https://doi.org/10.1097/00001573-200009000-00001

Shashi, T., \& Rakesh, S. (2017, September). Deep Breathing Exercise and Its Outcome among Patient with Abdominal Surgery: A Pilot Study. International Journal of Nursing Science, 7(5), 103-106.

Shenkman, Z., Shir, Y., Weiss, Y.G., Bleiberg, B., \& Gross, D. (1997). The effects of cardiac surgery on early and late pulmonary functions. Acta Anaesthesiol Scand, 41, 1193-1199. https://doi.org/10.1111/j.1399-6576.1997.tb04865.x

Shi, A. (2006). The effect of breathing exercises on postoperative lung function and quality of life of patients with lung cancer. Chin J. Misdiagn, 4764-4765.

Urell, C., Westerdahl, E., Hedenstrom, H., Janson, C., \& Emtner, M. (2012). Lung function before and two days after open-heart surgery. Crit Care Res Pract, 291628. https://doi.org/10.1155/2012/291628

Westerdahl, E. (2015). Optimal technique for deep breathing exercises after cardiac surgery. Retrieved 10 June 2015, from https://www.researchgate.net/publication/263206067

Westerdahl, E., \& Fagevik Olsén, M. (2014). Chest physiotherapy and breathing exercises for cardiac surgery patients in Sweden-A National survey of practice. Elisabeth Westerdahl.

Westerdahl, E., Lindmark, B., Bryngelsson, I., \& Tenling, A. (2003). Pulmonary function 4 months after coronary artery bypass graft surgery. Resp. Med., 97, 317-322. https://doi.org/10.1053/rmed.2002.1424

Westerdahl, E., Lindmark, B., Eriksson, T., Friberg, O., Hedenstierna, G., \& Tenling, A. (2005). Deep-breathing exercises reduce atelectasis and improve pulmonary function after coronary artery bypass surgery. Chest, 128, 3482-3488. https://doi.org/10.1378/chest.128.5.3482

Wren, S.M., Martin, M., Yoon, J.K., \& Bech, F. (2010). Postoperative pneumonia-prevention program for the inpatient surgical ward. J. Am. Coll. Surg., 210(4), 491-495. https://doi.org/10.1016/j.jamcollsurg.2010.01.009

Yamane, T. (1967). Statistics an Introductory Analysis (2nd ed.). New York Harper and Row.

Yanez-Brage, I., Pita-Fernandez, S., Juffe-Stein, A., Martinez-Gonzalez, U., Pertega-Diaz, S., \& Mauleon-Garcia, A. (2009). Respiratory physiotherapy and incidence of pulmonary complications in off-pump coronary artery bypass graft surgery: An observational follow-up study. BMC Pulm Med., 9, 36. https://doi.org/10.1186/1471-2466-9-36

\section{Copyrights}

Copyright for this article is retained by the author(s), with first publication rights granted to the journal.

This is an open-access article distributed under the terms and conditions of the Creative Commons Attribution license (http://creativecommons.org/licenses/by/4.0/). 